\title{
Sin exclusiones: catolicismo, mujeres y liderazgo distribuido
}

\author{
SANDRA ARENAS \\ Universidad Católica de Temuco \\ sarenas@uct.cl \\ (iD) https://orcid.org/0000-0002-5722-8538
}

Resumen: El corolario de los abusos de poder en la Iglesia obliga a pensar en la lógica que rige a la autoridad eclesial y a los liderazgos que la ejercen. La teología conciliar del triplex munus de Jesús, aplicado a todos/as y a la vez a algunos, dejó instaladas ciertas yuxtaposiciones doctrinales que no han generado mayor movimiento hacia una homogeneidad varones-mujeres, en la asunción de liderazgos y administración del poder eclesial. En este trabajo pondremos en conversación la teoría crítica del liderazgo distribuido y la dinámica de sinodalización de la Iglesia, postulando que un liderato construido y ejercido comunitariamente demanda características del poder distintas a las actuales y conlleva, como correlato, la inexorable inclusión de mujeres.

Palabras clave: Inclusión, liderazgo distribuido, sinodalización, poder eclesial

Abstract: The background of power abuses in the Catholic Church have led us to consider the logic behind both ecclesial power and leadership. The conciliar theology of the triplex munus of Jesus applied to all and, at the same time, some members of the clergy, installed several doctrinal juxtapositions that have prevented the development of an homogeneity between men and women in positions of leadership and administration of ecclesial power. In this paper, we discuss the critical social theory of distributed leadership with the dynamics of synodalization of the Church. We postulate that a leadership built and exercised communally demands characteristics of power that are different from current ones and entails as a correlate the inexorable inclusion of women.

Key words: Inclusion, distributed leadership, synodalization, ecclesial power. 
El corolario de los abusos de poder en la Iglesia obliga a pensar en la lógica que rige a la autoridad eclesial y a los liderazgos que lo ejercen, con herramientas propias y prestadas. En toda la historia de la Iglesia se han ocupado mediaciones seculares para la construcción de doctrinas, teologías, espiritualidades y sistemas de gobernanza. Esta es una consecuencia de esa binomial naturaleza declarada en Lumen gentium (LG) 8, irrenunciable, lo que somete constantemente a la Iglesia a las preguntas sobre ¿qué dice de sí misma? y ¿para qué existe? Las respuestas a lo largo de la historia han ido fraguando su depósito tradicional, y están sujetas a desarrollo y profundización, recomprensiones, actualización y renovación.

El Concilio Vaticano II reinstaló el sacerdocio bautismal, aunque desarrolló una teología laical que ha mostrado quedar en deuda con la inclusión de sujetos eclesiales. Hubo silencio acerca del rol de las mujeres en las estructuras de la Iglesia y, en consecuencia, en los roles de autoridad y de ejercicio de liderazgos y poder. El tria munera de Jesús se aplica a todos/as y, a su vez, a algunos, creando una yuxtaposición que ha planteado importantes preguntas teológicas y canónicas, ralentizando el proceso de inclusión de mujeres en roles de liderazgo que se desprenden del ejercicio de ese triplex munus. Se trata de entender por qué, si hay participación común, no hay movimiento hacia una mayor homogeneidad varones-mujeres en la asunción de liderazgos y administración del poder eclesial. Este hecho conduce a pensar que detrás de la tensión clérigos-laicado ha persistido una tensión de género que, si fuese resuelta, ayudaría en el proceso de inclusión de sujetos.

En este trabajo pondremos en conversación la teoría crítica del liderazgo distribuido con la dinámica de sinodalización de la Iglesia, como otro lente para observar la complejidad del tema en la institución, al postular que un liderazgo construido y ejercido comunitariamente demanda características de poder distintas a las actuales, y conlleva como correlato la inexorable inclusión de mujeres. El liderazgo distribuido es una herramienta heurística, reconoce a cada miembro de una comunidad, quienes se involucran en la misión y asumen la responsabilidad en el diseño e implementación (y también en los eventuales fracasos); se controla el poder con menos riesgos de exclusión en los liderazgos ${ }^{1}$.

En consecuencia, en la primera parte (1) tomaremos algunos elementos del marco teológico-doctrinal y jurídico sobre mujeres, poder y liderazgo eclesial, para luego analizar la dinámica sinodal de la Iglesia en diálogo con la teoría del liderazgo distribuido (2) y arribar a algunas conclusiones, siempre provisorias.

\footnotetext{
${ }^{1}$ El tema "mujeres y ministerios en la Iglesia" es abordado en profundidad en otra contribución de este mismo volumen.
} 


\section{MARCO TEOLÓGICO-DOCTRINAL Y JURÍDICO CONTEMPORÁNEO SOBRE MUJERES, PODER Y LIDERAZGO ECLESIAL}

El Vaticano II reinstaló el sacerdocio bautismal, aunque desarrolló una teología laical que ha mostrado quedar en deuda con la inclusión de sujetos eclesiales. Hubo silencio acerca del rol de las mujeres en las estructuras de la Iglesia y, en consecuencia, en los roles de autoridad y de ejercicio de liderazgos y de poder. El mensaje conciliar es algo vago e inconsistente, lo que ha influido en la concretización jurídica posterior. Sobre las mujeres en la vida eclesial, Apostolicam actuositatem apenas sostiene lo siguiente:

Como hoy las mujeres tienen una participación cada vez más activa en toda la vida en sociedad, es muy importante que su participación también aumente en los diversos sectores del apostolado de la Iglesia (AA 9)².

Miremos un poco más de cerca este silencio e inconsistencia doctrinal.

\subsection{Concilio, laicado y mujeres}

Sólo en la segunda sesión del Concilio (el 22 de octubre de 1963), cuando se retomaba en el aula el debate sobre la naturaleza y el rol de la Iglesia, el Cardenal belga Leo Suenens pronunció un discurso que sigue teniendo vigencia: "Me parece que las mujeres constituyen casi el 50\% de la humanidad [...] ¿Por qué siquiera estamos debatiendo la realidad de la Iglesia, cuando la mitad de ella no está presente aquí?”3. En respuesta a esa intervención, veintitrés mujeres (diez religiosas y trece laicas ${ }^{4}$ ) fueron escogidas como auditoras conciliares ${ }^{5}$. Hasta la muerte del Papa Juan XXIII (ocurrida cuando el Concilio aún no terminaba), solo unas pocas periodistas, entre unos mil reporteros, circulaban en la asamblea conciliar, sin acceso a la comunión eucarística ${ }^{6}$. La tensión entre un espíritu de renovación y las aprehensiones por la presencia de mujeres atravesaría todo el evento. En un espacio eclesial de alta concentración de poder, la audición era el único sentido capaz de ser

${ }^{2} \mathrm{Y}$ en sólo otros dos lugares se habla de las mujeres explícita y directamente: GS 9 y GS 60. Aunque el Concilio se proponga contrapesar la discriminación social de género, atendiendo a la dignidad de la mujer y a su plena participación (en lugares como GS 29) no se hace cargo de la discriminación interna.

${ }^{3}$ Cf. Acta Synodalia II/3, 177.

${ }^{4}$ En mayo de 1964, la Unión Mundial de las Organizaciones Femeninas Católicas (UMOFC), que agrupaba a 36 millones de mujeres de alrededor de 110 organizaciones representativas de los cinco continentes, había enviado a la Secretaría General del Concilio una lista de posibles mujeres auditoras. Desde ahí se construyó la definitiva, de manera progresiva.

${ }^{5}$ Los trabajos conciliares llevaban ya más de 3 años y hasta ese momento sus miembros eran solo varones, con 13 laicos auditores.

${ }^{6}$ C. McEnroy, Guests in Their Own House. The Women of Vatican II. (Crossroad, New York 1996) 99. 
desplegado por las mujeres. Bernard Häring insistió, sin embargo, en que si se convocaba a mujeres debía otorgárseles participación en la formulación de los documentos, y gracias a ello algunas fueron invitadas a atender las reuniones de determinadas comisiones: apostolado de los laicos, vida religiosa e Iglesia en el mundo moderno. Por esa participación se relevó más la discriminación de género, aunque siempre en contexto social, no intra-eclesial ${ }^{7}$.

$\mathrm{Al}$ final del Concilio se formó un comité provisional para el apostolado de los laicos, y el 6 de enero de 1967 Pablo VI creó el Consejo de los Laicos, un nuevo organismo en el gobierno central donde se incorporó a una mujer a la curia romana ${ }^{8}$. Aun así, el proceso de inclusión no ha sido lineal y todavía está inconcluso, nunca exento de conflicto. Por ejemplo, en enero de 1970 se rechazó el nombramiento de una consejera de Embajada en el Vaticano, bajo el argumento de que no estaba en la tradición de la Iglesia que una mujer ocupara tal posición. Aquello generó un debate ya que se trataba de una suerte de intromisión, pues las inclusiones mencionadas se inscribían en el marco de las excepciones (discutidas en cada momento). Y ha sido así hasta ahora. Durante el pontificado actual se han incrementado dichas inclusiones ${ }^{9}$, pero creemos que no se trata de engrosar esa lista acríticamente. El riesgo de que permanezcan en el plano de las excepciones, al carecer de un marco teológicodoctrinal y jurídico, es enorme.

Observamos que, desde los movimientos de renovación de la primera mitad del siglo XX, el Concilio Vaticano II pareció equilibrar conceptualmente el aparato de gobierno, con una teología del laicado y de los ministerios al interno de una renovada comprensión de Iglesia. Pero la narrativa sobre el poder y los liderazgos no varió sustancialmente, en especial respecto a una inclusión

${ }^{7}$ Esta historia está cada vez mejor documentada. Ver, por ejemplo: G. AlBERIGO - J. KomonchaK (eds.), History of Vatican II. Vol.IV- Church as Communion: Third Period and Intersession, September 1964-September 1965, (Leuven, Orbis - Peeters 2004) 19-27; R. GOLDIE, "Una donna al Concilio. Ricordi di una 'uditrice", Revista de Scienze Religiose del Pontificio Seminario de Molfetta, 2 (1988) 375-390; A. MiCELI, Tra storia e memoria, (CIF, Roma 1994); D. Dirkje, The Tenacious Voice of Women. Rie Vendrik and the Pontifical Commission on Women in Society and in the Church, (Utrecht 2002); A. VALERIO, Madri del Concilio. Ventitré donne al Vaticano II., (Carocci Editore, Roma 2012).

8 Rosemarie Goldie, australiana, como secretaria del Consejo. El proceso posconciliar australiano merece ser tenido en cuenta, un buen trabajo en nuestra materia en P. FOX, "Power and Leadership of Women Within the Catholic Church in Australia", The Australian Catholic Record 95/1 (2018) 10-19. El papa nombró a otras mujeres en el Consejo de Justicia y Paz. Cf. A. Leflaive, La femine et l'Eglise, (France-Empire, Paris 1968) 186-188.

${ }^{9}$ En enero de este año, por ejemplo, la Dra. Francesca Di Giovanni asumió como subsecretaria en la Secretaría del Estado Vaticano, el sector diplomático de las relaciones multilaterales. Algo análogo ha pasado en los dicasterios para las comunicaciones, para los laicos y para la vida consagrada. Durante estos últimos años, ha ido quedando más en evidencia que para ser prefectos de la curia romana no necesariamente hay que ser presbítero, ni varón. 
efectiva de mujeres. Las inconsistencias internas han quedado en evidencia en el proceso de recepción, incluido en los silencios de algunas iglesias regionales, como es el caso de América Latina ${ }^{10}$. Una de las incongruencias más relevantes para abordar poder-liderazgos e inclusión de las mujeres es la trazada en Lumen gentium (LG), a propósito de la doctrina del tria munera: existe una diferenciación entre el laicado masculino y femenino, evidenciando que la tensión clérigoslaicado es más bien una tensión varones-mujeres ${ }^{11}$. Tras un simposio sobre el lugar de la mujer en la Iglesia, celebrado en París en abril de 1969, se planteó el deseo de que el derecho canónico fuese aggiornado precisamente en estas materias $^{12}$; pero veremos que, en 1983, no se hizo el tránsito adecuado. Los problemas hermenéuticos entre la doctrina conciliar y su aplicación práctica han quedado en evidencia. Revisemos el problema.

\subsection{Las inconsistencias teológico-doctrinales y jurídicas sobre la doctrina del "tria munera": tensión varones-mujeres en la Iglesia}

Los tres oficios de Cristo (o tria munera) es una rúbrica utilizada retrospectivamente por la teología para referirse a los oficios sacerdotal, profético y real de Jesús después de la resurrección. Esta constituye el marco general de los documentos conciliares, en particular de $\mathrm{LG}^{13}$, y es el principio subyacente en la eclesiología del Código de Derecho Canónico de 1983. El tria munera de Jesús se aplica a todos y, al mismo tiempo, se individualiza a los ministros ordenados (LG 25-29), a los laicos en la Iglesia y en el mundo (LG

${ }^{10}$ Muy escasa literatura sobre poder y mujeres: M. PINTOS DE CEA-NAHARRO, "El derecho de las mujeres a la plena ciudadanía y al poder de la toma de decisión en la Iglesia", Alternativas 10/269 (julio-diciembre-2003) 149-161; I. CORPAS DE POSADA, "Liderazgo y servicio en la tradición católica: lectura de textos en perspectiva de género", Theologica Xaveriana 61/1, no. 171 (ene.-jun. 2011) 31-63; D. Rocco TEDESCO, "Iglesia y poder: el rostro oculto de lo femenino”, Theologica Xaveriana 62/1, no. 173 (ene.-jun. 2012) 169-198. Una teología sistemática del poder en la obra de L. BOFF, Iglesia: carisma y poder. Ensayos de eclesiología militante, (Sal Terrae, Santander 1982) y C. BOFF, "Teología do poder", Revista de cultura vozes 85/1 (1991) 36-47. Sobre liderazgo: M. Solís, "Iglesia. El liderazgo cristiano en América Latina", Misión 60/16 (1997) 6-11; y dos buenos trabajos en revista Medellín: J. L. PÉREZ GUADALUPE, "Gestión y liderazgo eclesial: un desafío para la misión de la Iglesia", Medellín 34/135 (sep. 2008) 521-538; "Estructura y cultura organizacional en la Iglesia católica", Medellin 34/136 (dic. 2008) 687-717. A partir del 2010 empieza a surgir literatura sobre abusos del poder, por ejemplo: P. RiCHARD, "Pedofilia y poder sagrado", Senderos 32/95 (ene.-abr. 2010) 195-202.

${ }^{11}$ La discusión sobre el estatus y rol del laicado en el posconcilio se inscribe dentro de estas coordenadas, ver: A. Dulles, "Can the Word 'Laity' Be Defined?", Origins 18/29 (29 December 1988) 470.

12 Secrétariat de l'Union Mondiale des Organisations Féminines Catholiques, "Mémorandum sur le Droit Canon", La femme dans l'Eglise et le Droit Canon (Paris 1969) 72.

13 O. RusH, "The Offices of Christ, Lumen Gentium and the People's Sense of the Faith", Pacifica 16 (June 2003) 137-152. 
34-36) añadiendo, sin mayor explicación, que hay una diferencia esencial entre los ordenados y los no ordenados, precisamente en su ejercicio. La yuxtaposición de estas tres posiciones ha planteado importantes preguntas teológicas ${ }^{14}$, que son también canónicas y que han ralentizado el proceso de inclusión en la práctica jurídica y pastoral. Se trata de entender por qué, si hay participación común, no hay movimiento hacia una mayor homogeneidad de género en la asunción de liderazgos y administración del poder eclesial. Interpretar y/o discernir el espíritu y la letra conciliar ${ }^{15}$ - y la norma que la acompaña - es complejo. Por un lado, habría que destrabar los excesos de centralización que genera el vínculo orden-ministerios-liderazgos-gobierno eclesial y, por otro, el exceso de masculinización. Enfrentar este primer punto ayudaría a resolver el segundo antes mencionado.

Rush sostiene que hay que comprender de manera dinámica la relación que el Concilio establece entre la infalibilidad in credendo y la in docendo en LG y Dei verbum (DV). Postula que DV 8 involucra tres voces en la recepción de la revelación, no sólo el sentir de los fieles y el magisterio, sino también a la teología de escuela. LG 12, 25 y DV 8 hablan del sentido dinámico del Espíritu que genera la tradición viva de la Iglesia a lo largo de la historia, estableciendo una relación interactiva entre tres grupos ${ }^{16}$. Sin embargo, esta conspiratio entre obispos y fieles permanece sin desarrollo en las tesis yuxtapuestas del Vaticano II sobre el oficio del magisterio, dando a veces la impresión de una relación pasiva entre obispos y fieles, esa división entre una ecclesia docens y una ecclesia discens ${ }^{17}$. Esto se ha convertido en un problema práctico, canónico y pastoral, al promover esa división dual y al considerar la participación del laicado y de los ordenados -en el triplex munus ${ }^{18}$ - vis-à-vis en el poder de gobernanza. La participación ontológica en el munus sanctificandi (con excepción del canon 835) -incluso entre los ordenados entre sí- según sus rangos y cargos, es confusa.

${ }^{14}$ Está en la base de las yuxtaposiciones teológicas conciliares según se ha demostrado. Ver O. RusH, Still Interpreting V atican II: Hermeneutical Principles, (Mahwah, NJ: Paulist 2004) 27-43, 49.

15 Espíritu y letra del Vaticano II, dos categorías hermenéuticas clave en el proceso de recepción. El espíritu refiere a lo que surgió de todos los debates, presentaciones escritas, redacción, vota. La letra refiere a la forma final de los dieciséis documentos, a través de los cuales se expresaron los consensos. Esto también es cierto del Código de Derecho Canónico. Los siete libros y los 1752 cánones no presentan un perfecto tratado, sistemático y metódico.

${ }^{16}$ Cf. O. RusH, The Vision of V atican II: Its Fundamental Principles, (Liturgical Press, Collegeville, MI. 2019) 303.

${ }_{17}$ Cf. O. Rush, The Eyes of Faith: The Sense of the Faithful and the Church's Reception of Revelation, (The Catholic University of America Press, Washington, DC 2009) 183.

18 El mismo concepto de munus tiene significados diversos en la interpretación actual del derecho canónico. Cf. J. Huels, “Towards Refining the Notion of 'Office' in Canon Law”, The Jurist 70 (2010) 396-433. Más que función u oficio, acá, munus debe comprenderse como regalo. 
El canon 129 parece restringir la posesión del poder de gobernanza a quienes detentan el sacramento del orden, sosteniendo a la vez que los laicos pueden cooperar o compartir ese ejercicio de autoridad. No obstante, la interpretación ha favorecido un orden que enfatiza el poder de gobierno como fundamental para otros poderes o ministerios, como el de santificación o de enseñanza. Este poder regula jurídicamente a los demás ${ }^{19}$. Los canonistas debaten este postulado, argumentando que es una clásica fórmula pragmática de compromiso, diseñado para mejorar el vínculo teórico entre el estado clerical y la posesión monolítica del poder de gobierno; junto a la praxis, que refleja que los laicos podrían usar algún rol de gobernanza ${ }^{20}$. Sin embargo, parece más consistente anclar en el sacerdocio común de cada bautizado/a la capacidad de ejercer el poder de gobierno ${ }^{21}$. Seguimos trabados en esto.

Por otro lado, hemos podido observar el silencio conciliar acerca del rol de la mujer en la Iglesia, con toda la deuda doctrinal que conlleva ${ }^{22}$. Aun pensando en la buena intención de tratar a varones y mujeres desde el principio doctrinal de igualdad fundamental, la limitación de la ordenación exclusivamente a los varones (CIC, canon 1024) y la estrecha conexión entre la ordenación y la elegibilidad para puestos de autoridad (por ejemplo, cánones 129, 150 y 521), es un gran obstáculo para la inclusión ${ }^{23}$. Pero no es el único. Las restricciones para las mujeres en los ministerios laicales de acolitado o lectorado, en la proclamación del Evangelio o en la posibilidad de ejercer como juezas en

19 Un buen ejemplo es el del obispo, o la autoridad competente: utilizando su poder de gobierno concede dispensas relativas a los sacramentos (ver cánones 1047, 4; 1078-1080; $1127,2)$ y mandata el ejercicio de la teología (ver canon 812 ).

${ }^{20}$ No es el enfoque de este trabajo, pero vale la pena resituar el modo en el cual se entiende la dinámica de la jerarquía en la Iglesia. Después de un detallado estudio histórico-teológico, Brian Borne recuerda que la representación estructural de la Iglesia en cada época ha sido afirmada y, a la vez, traicionada. Concluye la investigación diciendo que: "the dynamics of hierarchy in the Church will, at their best, be understood only as forms of pastoral care and historical continuity, and, at their worst, be used as tools of management and control: perverted into instruments of power and repression". Cf. B. BORNE, "Homo Hierarchicus and Ecclesial Order", International Journal for the Study of the Christian Church $7 / 1$ (February 2007) 16-28, 26-27.

${ }^{21}$ Cf. J. Coriden, "Lay Persons and the Power of Governance", The Jurist 59 (1999) 338. Recuerda, además, que el poder de gobernanza es de derecho positivo eclesiástico y no de derecho divino. Ya P. Hünermann había advertido la ausencia en LG de un párrafo directamente relacionado con la participación de todo el pueblo de Dios en el munus regendi. Cf. P. HÜNERMAnN, Theologischer Kommentar zum Zweiten Vatikanischen Konæil, (Herder, 2004) 403.

22 Un sucinto panorama histórico donde son también resaltadas las limitaciones del Vaticano II en estas materias, en C. Militello, "Women in the church: Models of the past-challenges of today", en Catholic Women Speak Network (eds.), Catholic women speak. Bringing our gifts to the table (Paulist Press, New York 2015) 7-10.

${ }^{23}$ Cf. J. A. Coriden, "Highlights of the Revised Code", The Jurist 44 (1984), 28-40, 33. 
tribunales eclesiásticos, son ejemplos claros. Se ha exhibido en el postconcilio un claro sesgo de género, con los impedimentos para el servicio del altar, la impartición de justicia o la proclamación del Evangelio. De hecho, la aplicación jurídica de la eclesiología conciliar parece imprimirle mayor intensidad y elevación al sacerdocio ministerial por sobre el bautismal, femenino en específico. Como es sabido, en 1983 la decisión sobre si las mujeres pueden servir el altar se deja al Ordinario del lugar, dependiendo de las circunstancias de la diócesis ${ }^{24}$. Sin embargo, en la carta del 15 de marzo de 1994 de la Congregación del Culto Divino se corrigió la norma, dejando a las conferencias episcopales en libertad de admitir a mujeres en el servicio del $\operatorname{altar}^{25}$; la exclusión se ha debido únicamente a prejuicios instalados de género, los que han continuado en no pocas iglesias locales. El segundo ejemplo es algo distinto, aunque el canon 1421, 2 al referirse a los laicos, no hace distinción entre los varones y las mujeres nombrados jueces, el motu propio de Pablo VI del 28 de marzo de 1971, en cambio, restringía el nombramiento de las mujeres laicas. Y la aplicación e interpretación canónica de la doctrina tomó una ruta, la que parecía indicar que los varones en la Iglesia son los únicos capaces de impartir bien la justicia. Con todo, algunas iglesias locales han ido gradualmente tomando decisiones en otra dirección ${ }^{26}$. En el caso de la predicación, se desconoce que la mujer, al igual que el varón, tiene una función eclesial kerigmática irrenunciable, y que no se agota únicamente en la catequesis. Otras iglesias cristianas lo entendieron mucho más temprano (porque han ido madurando, por más tiempo, la igualdad fundamental que el bautismo otorga a varones y mujeres). La proclamación fiel del Evangelio tiene forma femenina y masculina. Acerca del munus profético, de autoridad y de enseñanza en la Iglesia, estudios recientes sobre el debate conciliar revelan que, incluso en la primera sesión del Concilio, hay vestigios de inclusión del conjunto de la membresía al tratar, como una consecuencia lógica de la teología bautismal, la posibilidad de que todo el pueblo de Dios esté involucrado en la enseñanza

${ }^{24}$ Wijlens sostiene que, aunque la palabra cooperación se utiliza en el canon 129 para establecer la naturaleza de la actitud de la participación de los fieles laicos, en la función de gobierno de la Iglesia y la relación entre los fieles laicos y los ordenados en términos de ministerio y gobierno, debe entenderse como complementariedad entre el ordenado y el laico en el oficio de gobierno de Cristo en la Iglesia. Cf. M. WiJLENS, "Ecclesial Lay Ministry, Clergy and Complementarity", CLSA Proceedings 64 (2002) 39.

25 Johnson sostiene que el Código de 1917 tenía como objetivo promover la pureza del sacerdote manteniendo al mínimo su contacto con las mujeres. Por contraste, en la parroquia actual -sostiene- el sacerdote está involucrado en interacciones ministeriales con mujeres, de modo que, tener una mujer que sirva en el altar, difícilmente puede hacer alguna significativa diferencia. Cf. J. G. Johnson, "Who May Serve Mass? A Quest for the Ius vigens", The Jurist 48 (1988) 692-708, 706.

${ }^{26}$ Gracias a ese ejercicio local, por ejemplo, la canonista chilena Sofía Seguel ejerce como jueza metropolitana del tribunal canónico de la Arquidiócesis de Washington desde 2017. 
infalible de la Iglesia; postura que corrió en paralelo hasta decantar, en la síntesis, en una notoria yuxtaposición ${ }^{27}$.

Los liderazgos de mujeres en la administración diocesana han sido escasamente promovidos, fundamentalmente por vincularlos al ministerio ordenado. En los últimos años hemos asistido a los intentos más decididos de inclusión, pero mientras las buenas intuiciones pastorales no conozcan un correlato doctrinal (y una eclesiología que sostenga esas intuiciones) se tratará de mera cosmética, que no imprimirá ningún cambio de cultura eclesial capaz de sostener reformas estructurales. En Chile, por ejemplo, entre el año 2019 y el 2020, se ha mandatado la administración de tres parroquias a religiosas: Marta García en la diócesis Chillán (2019) y Julia Órdenes y Beatriz Garrido en la de Copiapó (2020), bajo la figura de responsable de parroquia. Se trata de una creciente praxis, como reveló el proceso sinodal panamazónico, cuya causa principal ha sido la escasez de presbíteros y no, en rigor, una búsqueda de inclusión consciente, amparada por una profundización teológico-doctrinal. Es cierto que, sobre el munus regendi ha acontecido un gradual desplazamiento conceptual en el postconcilio, desde la clásica potestad de jurisdicción a la función de gobierno, introduciendo la ministerialidad ${ }^{28}$ (más allá de ministerios laicales establecidos canónicamente), lo que está un poco más en sintonía con el carácter de servicio que toda potestad o función debe exhibir en la Iglesia y donde este tipo de liderazgos encuentra más sustento.

Entre los aprendizajes que la crisis de abusos nos ha dejado, reconocemos fundamentalmente el hecho de que la realidad hay que mirarla de frente, reconociendo, en consecuencia, que el fondo de la tensión clero-laicado es y ha sido también una tensión de género en la Iglesia. Revisitar la historia, la doctrina y la norma con estos lentes ayudará a destrabar procesos internos, y revitalizará la misión comunitaria. Por lo pronto, al destrabar la vinculación orden-potestad de gobierno, tendrían cabida las formas ministeriales que el actual escenario eclesial exige.

Los debates teológicos actuales, en torno a la noción de Iglesia en estado sinodal, debiesen ir pavimentando el camino de los cambios estructurales y doctrinales que una transformación requiere.

\footnotetext{
${ }^{27}$ Cf. P. DE MEY, "The Actors Involved in the Exercise of the Prophetic office in the Church", Studia Canonica 53 (2019) 127-164, 140, nota 60.

${ }^{28}$ Hay abundante bibliografía, se puede consultar F. REA, "L'esercizio della potestà giudiziaria del fedele laico attraverso il prisma della Potestas gubernandi in Ecclesia. Sollecitazioni teologiche e canonistiche per una 'Chiesa in uscita"', Stato, Chiese e pluralismo confessionale 37 (2018) 18, en línea: https://www.statoechiese.it/contributi/lesercizio-della-potestagiudiziaria-del-fedele-laico-attraverso-il-prisma/chiesa-cattolica, (consulta: 30/10/2020).
} 


\section{Estado SINODAL DE LA IgLESIA Y TEORÍA DEL LIDERAzgo DISTRIBUIDO}

Como nos enseña el reciente proceso sinodal panamazónico, la evangelización y la reforma de la Iglesia no se excluyen; más bien indican que sólo un cambio de cultura eclesial y de estructuras ad hoc posibilita una adecuada misión. Aunque no hayan llegado todas las transformaciones esperadas con ese proceso, se demostró que las prácticas eclesiales actuales son insuficientes, y que se precisa encontrar nuevas formas significativas de servir. Esto afecta directamente a la inclusión femenina, a la diversificación de los liderazgos y equilibrio del poder, y al lugar del conflicto en la Iglesia, dentro de una eclesiología que pretende incluir de manera efectiva la diversidad de voces. Con la dinámica sinodal de la Iglesia, el Papa actual promueve una eclesiología que amplía la participación en tomas de decisiones, distanciándose del ámbito únicamente clerical y tendiendo hacia un proceso de escucha paciente ${ }^{29}$; al ampliarse se diversifica, lo que hace pleno espacio a las diferencias y también a eventuales conflictos.

Dado que la tradición institucional se ha construido siempre con mediaciones foráneas, que existe poca experiencia de diversificación del liderazgo y del poder, y que este proceso de sinodalización de la Iglesia está in fieri, vamos a dialogar con una teoría contemporánea -ajena a la teología- sobre liderazgos y poder; tal vez algo podamos aprender de ella. La teoría emergió en un contexto institucional diverso, pero en cierta medida comparte el horizonte de proyecto comunitario con alcance social y pretensiones de inclusividad. Su eventual relevancia no está en el nivel de la receta aplicable acríticamente, sino en el de ser una herramienta heurística, un lente a través del cual examinar y comprender mejor la interrelación y las acciones del liderazgo con el consecuente ejercicio del poder.

La teoría anglosajona del liderazgo distribuido se ha posicionado como un reemplazo potencial de formas anteriores de autoridad, criticadas negativamente por su ética o eficacia: aquellas relacionadas con el líder heroico o carismático que ejerce un poder monolítico (las transaccionales, o de arriba hacia abajo). El liderazgo distribuido, potencialmente, permite que todos/as participen en la dirección de la comunidad, basándose únicamente en la

\footnotetext{
${ }^{29}$ Se amplía la literatura sobre esta materia: consultar la obra colectiva editada por el irlandés GERARD MANNION, "Francis's Ecclesiological Revolution: A New Way of Being Church, a New Way of Being Pope", en G. MANNION (ed.) Pope Francis and the Future of Catholicism: Evangelii Gaudium and the Papal Agenda, (Cambridge: Cambridge UP, 2017) 94. Con enfoques diversos, los dos artículos que siguen vinculan el estado sinodal de la Iglesia del Papa actual, al Concilio Vaticano II: O. RusH, "Inverting the Pyramid: The Sensus Fidelium in a Synodal Church", Theological Studies 78 (2017) 299-325 y A. Spadaro - C. GALLI, "La sinodalità nella vita e nella missione della Chiesa”, La Civiltà Cattolica 169/II, no. 4039 (2018) 55-70.
} 
capacidad de sus miembros, ya sea facilitado por el líder de turno o como resultado de la auto-organización. Algunos han presentado esta idea como análoga a una pieza de jazz, donde se consensua un ritmo básico, un marco general, dentro del cual los individuos toman el control de las diferentes partes de manera fluida ${ }^{30}$. En perspectiva de dinámica sinodal de la Iglesia, la imagen es mucho más elocuente que aquella tradicional de la música orquestal, movida por un director con una partitura que controla cada una de las partes. Al lograr la participación de un grupo más amplio de miembros, la implementación de un cambio resulta más efectivo. Algunos textos van más allá, al afirmar que el liderazgo distribuido crea más oportunidades a la comunidad; y éstas, de hecho, estarían abiertas para todos/as ${ }^{31}$. Dentro de este modelo, disminuyen significativamente los límites para construir inclusión ${ }^{32}$. La identificación de las dimensiones de la práctica del liderazgo, y la articulación de las relaciones entre los miembros de la comunidad que lo sostiene ${ }^{33}$, se convierte en una forma recomendada de práctica de gobernanza.

¿Cómo funciona la teoría y cómo se articula el poder dentro de ella? Hay dos ángulos desde los que puede resultar útil considerar la relación de poder y liderazgo distribuido. El primero es el modo en cómo se concibe el poder en ella y, en segundo lugar, cómo la misma teoría del liderazgo distribuido puede ser una promulgación de poder. Esta relación se tensiona de manera diversa en cada una de las tres visiones de poder que la teoría considera: la visión unidimensional, la bidimensional y la tridimensional ${ }^{34}$. En la unidimensional, la idea de poder opera como algo que un individuo o grupo posee y ejerce para dirigir a otro(s), o para evitar que actúe(n) de una manera particular, incluso para evitar el conflicto. Observable en episodios específicos donde los líderes, para conseguir su voluntad, pueden actuar como soberanos pasando por sobre los deseos y las resistencias de los demás ${ }^{35}$. Acá, quien guía conserva un papel de liderazgo autorizado, pero el liderazgo espontáneo de otros/as corre por debajo o en paralelo, sobre el cual el/la líder no tiene más control que otros miembros de la comunidad. Junto a esto, quien lidera utiliza su poder individual

30 A. HARRIS, "Distributed leadership: leading or misleading", Educational Management Administration \& Leadership 32/1 (2004) 11-24, 17.

31 "It does not necessarily give any particular individual or categories of persons the privilege of providing more leadership than others". Cf. J. MAСBЕATH, "Distributed leadership: paradigms, policy and paradox", en Leithwood K. - Mascall B. \& Strauss T. (eds.), Distributed Leadership According to the Evidence. (Routledge, London 2009), 41-58, 13.

32 Cf. N. BennetT y otros, Distributed Leadership, (NCSL, Nottingham 2003) 162.

33 Cf. J.P. SPILLANE y otros, "Towards a theory of leadership practice: a distributed perspective", Journal of Curriculum Studies 36/1 (2004) 3-34, 4.

${ }^{34}$ Cf. S. LuKES, Power: A Radical View. (Macmillan, London 1974).

35 S. HAlford - P. LeOnard, Gender, Power and Organizations. (Palgrave, Basingstoke 2001) 27-28. 
para crear el entorno, en el que el liderazgo distribuido pueda crecer, mediante el establecimiento de estructuras y procesos y el desarrollo de la capacidad de liderazgo de los miembros ${ }^{36}$; toma acciones asertivas e intencionadas para impulsar a las personas a asumir un papel dentro del modelo ${ }^{37}$.

En el enfoque bidimensional, el poder no opera imponiendo a las personas a que actúen de la manera deseada por otro/a, sino que fluye a partir de adaptaciones espontáneas de la comunidad, donde los liderazgos son empoderados por los mismos miembros. En ningún caso el poder es absoluto. Hasta cierto punto, está limitado o aumentado por la aprobación de otros/as y ejercido dentro de los límites relacionados con la comunidad local. Poder que se vincula, por ejemplo, al cuerpo colegiado del consejo pastoral diocesano, cuya existencia se justifica para proporcionar a la feligresía una institución que facilite el uso de sus dones y talentos en el gobierno de su Iglesia. El espíritu que alienta esta norma es que la Iglesia local es una porción del Pueblo de Dios donde la participación efectiva, la escucha y consulta al sentido de fe de toda su membresía es obligatoria. El Concilio falló en la previsión de las consecuencias prácticas de esta doctrina ${ }^{38}$, y la interpretación no ha hecho siempre justicia al espíritu que la animó.

En la visión tridimensional de poder, los valores, acciones y pensamientos de cada uno/a, benefician a otros/as; los/as miembros son instruidos para aceptar que los intereses de uno/a sean también los propios, cultivando el posicionamiento en el lugar del otro/a. En este enfoque, es menos probable que surja conflicto, porque los miembros tratan de pensar como otros/as lo harían $^{39}$. Hay adaptación a la psicografía de los miembros, capturando aspectos positivos como el desarrollo de capacidades, la inclusión, la apertura de oportunidades y la autonomía ${ }^{40}$. Gradualmente, el poder unidimensional se vuelve obsoleto, otorgando a los miembros una dedicada formación para la corresponsabilidad en el liderazgo común.

Creemos que el principio pastoral subyacente al proceso de sinodalización de la Iglesia resiente las yuxtaposiciones de la teología conciliar del tria munera,

${ }^{36}$ Cf. M. Fullan, Turnaround Leadership. (RoutledgeFalmer, London 2006).

${ }^{37} \mathrm{~J}$. MURPHY y otros, "The role of the principal in fostering the development of distributed leadership”, School Leadership \& Management 29/2 (2009) 181-214.

38 Como consistentemente argumenta Myriam Wijlens, se dejó la tarea a los canonistas. El consejo pastoral diocesano es una institución relacionada con la Iglesia local, que no se identifica con el obispo. Cf. M. WijLens, "The Doctrine of the People of God and Hierarchical Authority as Service in Latin Church Legislation on the Local Church", The Jurist 68 (2008) 328-349, 332. Ver también L. Gooch, "Who Are the Women in Diocesan Leadership?", Origins 30 (2000-2001) 651-655.

${ }^{39}$ Cf. S. LuKES, Power: A Radical View.

${ }^{40}$ H. Youngs, "(Un)critical times? Situating distributed leadership in the field", Journal of Educational Administration and History $41 / 4$ (2009) 377-389. 
incluidas las inconsistencias en el proceso hermenéutico de recepción y aplicación práctica en el transcurso de estos sesenta años. La teoría del liderazgo distribuido toca una cuestión esencial para esta teología del sacerdocio bautismal, a saber, la autonomía de los miembros dentro de un proyecto comunitario, que emerge de los derechos fundamentales reconocidos jurídicamente ${ }^{41}$, tales como el derecho a la manifestación de la propia opinión sobre el bien de la Iglesia (canon 212,3) y el derecho a cultivar y vivir la propia espiritualidad (canon 214). A quienes se distribuye el liderazgo pueden manifestar opiniones disonantes de las de aquellos que actualmente lideran, y eso no constituye una amenaza para la cohesión interna, que es esencial para el éxito de la misión de la comunidad ${ }^{42}$. Tampoco lo es el cultivo de la propia espiritualidad (dentro de muchas formas posibles). Ese sentido de fe, canalizado estructuralmente, implica el ejercicio activo del poder de la palabra, de la profecía, de la predicación y de la teología ${ }^{43}$; con voces masculinas y femeninas, asumiendo la diversidad sin miedo al disenso, como si este per se quebrara la unidad. Ejercer el poder de la palabra dentro de estas coordenadas supone revisar serena y críticamente la comprensión de unidad eclesial, e incluso, de ortodoxia católica y configuración de ella. Si es cierto que la ortodoxia ha tomado forma por medio de elecciones epistemo-politicas, se ha forjado mediante la exclusión de narrativas alternativas ${ }^{44}$. En gran medida esto ha ocurrido históricamente con la exclusión de voces de mujeres, en el

41 Estos derechos son fundamentales, derivados del bautismo y no de una concesión eclesiástica.

${ }^{42}$ Cf. A. HARris, "Distributed leadership: according to the evidence", Journal of Educational Administration 46/2 (2008) 172-188, 178. Se ha propuesto que incluso la eficacia de la comunión entre las iglesias locales en una región determinada es menos propensa a verse amenazada por desacuerdo interno que por el distanciamiento proveniente del aislamiento mutuo. Cf. W. CoHEN, "Why Ecclésial Sfructures at the Regienal Level Matter: Communion as Mutual Inclusion", Theological Studies 75/2 (2014) 308-330, 311.

43 Aunque sin atención específica a la inclusión de mujeres en el proceso de sinodalización, tanto O. Rush como la Comisión Teológica Internacional advierten la falta de integración entre los actores del munus propheticus en los capítulos II y III de LG, y transforman el contenido de DV 10 en una circularidad tripolar, donde los fieles, el magisterio y los teólogos constituyen el rol de enseñanza en la Iglesia; mientras la CTI correlaciona el sensus fidelium, la colegialidad episcopal y la primacía papal dentro de su teología de la sinodalidad. Cf. O. RUSH, The Eyes of the Faith, 269 y COMISIÓN TEOLÓGICA INTERNACIONAL, La sinodalidad en la viday la misión de la Iglesia, (2018) número 94.

${ }^{44}$ Gruber sintetiza bien esta idea (surgida de un trabajo colectivo reciente): sostiene que el discurso sobre la pluralidad dentro de la Iglesia es un discurso sobre la lucha por la soberanía de la interpretación en la Iglesia. El derecho a definir la ortodoxia se enmarca en relaciones asimétricas de autoridad y de poder. La lucha por la correcta fe y la correcta práctica es, ante todo, una lucha acerca de quién tiene la voz para definir la ortodoxia católica: ¿quién puede participar en esta lucha, desde qué posición? Cf. J. Gruber, "Conclusion: Dissent in the Roman Catholic Church: A Response”, Horizons 45/1 (2018) 155-159. 
postconcilio y hasta en algunos espacios eclesiales concebidos como más abiertos. Las excepciones a las reglas eclesiásticas que han tendido a segregar, a menudo sólo han favorecido a varones, también en el campo del estudio y de la enseñanza de la teología. Aquellas penetrantes palabras de Suenens y Häring en el Concilio siguen resonando: ¿Por qué siquiera estamos debatiendo la realidad de la Iglesia, cuando la mitad de ella no está presente aquí, cuando la mitad de ella no participa en los debates doctrinales? ${ }^{45}$.

Con voluntad, diálogo y participación, se puede avanzar hacia la superación de las exclusiones, generando una cultura eclesial inclusiva, dentro de un proceso que incluya estructuras más apropiadas. Entre 2013 y 2015, en el norte de Francia, tres diócesis organizaron un consejo provincial donde promovieron la participación de más laicado del que el derecho canónico permite ${ }^{46}$; algo que acontece ahora en el así llamado sínodo alemán. Sin cuotajes, y con participación intencionada de mujeres de diversas generaciones. Esto se vuelve significativo, mostrando el desarrollo que puede tomar la sinodalidad más allá del marco canónico, que deja poco espacio para moverse fuera de una tradición clerical. Basta con mencionar que los miembros ex officio están vinculados a funciones desempeñadas mayoritariamente por presbíteros. El canon 443 contiene una cláusula restrictiva que obstaculiza la transición concreta fundada en el bautismo y no en el sacramento del orden.

Como vimos, una premisa fundamental de la teoría del liderazgo distribuido y su noción de poder es que los miembros que no tienen autoridad formal ganan poder a través del liderazgo distribuido. Dependiendo del enfoque, el poder puede percibirse como donado o incluso prestado por personas con roles de autoridad, pero también como resultado espontáneo de la pertenencia de los individuos a la comunidad. Así, el empoderamiento se logra no cambiando el tipo de actividades, sino resolviendo colectivamente quién decide lo que se hace y cómo se hace. Un cambio en la distribución del poder puede otorgar más autonomía y control sobre lo que la comunidad emprende. Una comprensión sinodal de la Iglesia supone estructuras que comprometan la voluntad comunitaria, sobre la base de discernimientos conscientes de los puntos ciegos que, inevitablemente, se inscriben en cualquier esfuerzo de representación y participación. $\mathrm{O}$, dicho de otra manera, hasta propuestas que pueden parecer muy audaces -como la de la ampliación del presbiterado a

45 A propósito de los recientes sínodos globales, sobre la familia y sobre los jóvenes, se ha relevado la necesidad de inclusión de mujeres, ver por ejemplo: N. HADEBE, "Not in our name without us' - The intervention of Catholic Women Speak at the Synod of Bishops on the Family: A case study of a global resistance movement by Catholic women", HTS Teologiese Studies/ Theological Studies 72/1 (2016) 1-9.

${ }^{46}$ Un buen trabajo sobre este sínodo en: A. JOIN-LAMBERT, "Le concile provincial, une chance pour la synodalité de l'Église”, Recherches de science religieuse 107 (2019) 301-320. 
varones probados- no están exentas de exclusiones (de género por lo pronto). No logran corregir las limitaciones clericales y de sexualidad de donde se distribuye hoy la autoridad sacramental de la Iglesia.

No va a haber reforma sin liderazgos representativos de toda la membresía eclesial $^{47}$, incluyendo al cincuenta por ciento históricamente excluido, todos/as siendo formados/as para distribuir el liderazgo y traspasarlo oportuna y adecuadamente. El poder en el catolicismo es de Cristo y, por el bautismo, pertenece a la comunidad que lo representa ejerciendo - en el Espíritu- el triplex munus. Mientras se ampare la unidad, en espacios seguros y sanos, el poder permanece en y para la comunidad y en vistas de su irrenunciable misión social.

\section{Algunas CONCLUSIONES}

Rastreando formas de liderazgo religioso, de ejercicio de una autoridad, se ve la comprensión de poder subyacente. El poder o la autoridad vinculada a Jesús, en los Evangelios, se distancia de las relaciones asimétricas o desiguales e instala una particular praxis del liderazgo. La relación que establece el líder con los discípulo/as y la gente, se expresa siempre mediante la experiencia del seguimiento, el cual nace de la ejemplaridad y no desde la sumisión. El grado de vinculación normativo que existe entre ese referente de poder (consignado en los textos del primer cristianismo de modos diversos) con la teología y doctrina actuales, resulta ser bien deficitario. No se trata de relaciones que se configuran desde la superioridad del que manda con el inferior que obedece.

Los modelos eclesiales siempre se han configurado tomando formas seculares de organización, liderazgo y gobierno, que tensionan la fidelidad a un origen (una interpretación del) y la adaptación a la historia (propio del catolicismo). El Vaticano II se inscribe en esta senda, y su implementación es necesaria en el proceso de renovación y reforma que quiso imprimir, contando con las limitaciones, enseñanzas yuxtapuestas, sus lecturas interpretativas críticas y las contingencias históricas. La cuestión que está en juego no es solo religiosa, sino también política, cultural e identitaria.

El catolicismo es una religión institucionalizada, nuestros signos y nuestros hechos deben reflejar constantemente los orígenes y para ello, hay que situar la fidelidad material a Jesucristo como adaptación y también con distancia o

\footnotetext{
47 Utilizando la mediación de estudios sociológicos, Serena Noceti advierte que toda reforma es un proceso donde se correlacionan la autoconciencia colectiva, las formas eclesiales y la transformación de estructuras e instituciones. Un proceso en el convergen de manera simultánea los tres niveles. Cf. S. NOCETI, "Reformas que queremos las mujeres en la Iglesia", en M. VIDAl i Quintero (ed.), Reforma y reformas en la Iglesia. Miradas críticas de las mujeres cristianas, Aletheia 14, (Verbo Divino, Navarra 2018) 107-126, 110-111.
} 
disimilitud. Resulta difícil comprender por qué un varón podría estar mejor posicionado que una mujer para simbolizar a Cristo en roles de liderazgo y ejercicio del poder en la Iglesia. Las mujeres participan por el bautismo -como los varones- del regalo sacerdotal, profético y real de Cristo. ¿Por qué entonces su función debe ser distinta de la de ellos? Las fórmulas de compromiso que han sellado las yuxtaposiciones reflejan resistencias políticas, mas no necesariamente argumentos teológicos, pero que igualmente han permeado el ordenamiento jurídico y, en consecuencia, han limitado la necesaria inclusión de sujetos eclesiales. Cuando se pone en conversación a la enseñanza, la norma, la praxis y la teología, se deduce que las mujeres pueden también representar a Cristo en el ejercicio concreto, profético y de gobierno. Se ha buscado una cierta correlación entre el significante y el significado, a partir de la cual sólo los varones pueden simbolizar adecuadamente a Cristo o representarlo, no sólo en la acción sacramental (acá no estamos abordando el tema de ministerios ordenados). Sin sincerar suficientemente el hecho de que las circunstancias históricas, las ideas sociológicas sobre el lugar de la mujer y otros factores, han fijado una tensión de género (no resuelta en el Concilio Vaticano II ni en su recepción posterior), el tránsito hacia un modelo organizacional inclusivo efectivamente será muy difícil.

El honesto contraste con la realidad nos sitúa en la paradoja de que el principio de igualdad que surge de la doctrina evangélica no ha sido suficientemente integrado, ni doctrinal, ni disciplinaria, ni jurídicamente, ni tampoco - en consecuencia - pastoralmente; cayendo en un doble discurso eclesiológico, a través del cual se ha desprotegido a la mitad de la membresía eclesial al quedar desprovistas de voz, voto, roles de liderazgo y ejercicio de poder. La teoría del liderazgo distribuido intenciona una relación más homogénea con los diversos actores y actrices.

En el postconcilio, al superar en parte el estadio de la desprotección del laicado en su conjunto, se han objetado varios presupuestos que fijan la tensión clero-laicado; pero no se ha resuelto la principal tensión eclesial interna, la que se da entre varones-mujeres, en primer lugar, al no sincerarla. Creemos que hacerlo ayudaría en el proceso de inclusión de sujetos eclesiales, en todas las esferas de la vida y misión de la Iglesia. Hemos proporcionado algunos ejemplos que refrendan esta conclusión.

La teoría del liderazgo distribuido podría ayudar en la medida en que se acepte y sincere ese nudo y se revisiten desde todos los ángulos sus presupuestos. La teoría opera básicamente bajo los principios de la inclusión de sujetos (generacional, de género, étnica) y sobre el principio de distribución y traspaso oportuno de los liderazgos y del poder. Se sostiene en la idea de que la comunidad que se lidera está constituida por una membresía sin diferenciación estratificada; no hay nadie mejor o peor dentro de ella. Y esa 
comunidad tiene una misión que excede sus propias fronteras, de modo que la distribución eficaz, inclusiva y oportuna del liderazgo colabora con la fecundidad de ese proyecto común, con irradiación social. Aunque pueda tener las limitaciones propias de cualquier teoría, creemos que puede ayudar en el proceso de sinodalización de la Iglesia, el cual implica una transformación de cultura eclesial y de estructuras organizacionales. La tarea es ardua, no ha sido integrada aún por todos/as y requiere traspasar las buenas intuiciones pastorales, aunque éstas provengan del obispo de Roma.

Lo demuestra la transición de la visión sinodal del Vaticano II a la implementación de esa visión en el Código de 1983; la renovación de la sinodalidad como modus operandi et vivendi de la Iglesia es tarea de una generación, no de un documento, pues no se decreta. Requiere de una acción consciente y decidida de parte de los pastores locales, bajo los criterios de inclusión real de voces de mujeres (no por concesión, sino por derecho), una reflexión sostenida de la comunidad teológica y canonista, paciencia de toda la membresía con los éxitos y fracasos de estrategias y acciones particulares, una conversión continua de hábitos que generen el tránsito cultural, nutridos por ejemplos que fluyan circularmente desde arriba y desde abajo, buenos modelos de consulta, de diálogo, de integración de los disensos y de discernimiento comunitario. 